\title{
Review
}

\section{Law, Rules, and Rationality}

\section{Norman S. Care†}

The Logic of Choice. By Gidon Gottlieb. New York: The Macmillan Company, 1968. Pp. 183. $\$ 5.95$.

I.

Professor Gidon Gottlieb's book ${ }^{1}$ is an attempt to make clear the logic of legal reasoning, and then to exhibit the implications of that logic for a number of problems in the philosophy of law. The contents of the book are interesting, even though the writing is poor and the text full of misprints; and the point of view expressed is important, even though it is not new in its basic themes. Regarding certain issues of jurisprudence, Gottlieb suggests that he subscribes to neither legal positivism nor a natural law philosophy, indicating that he is reaching for an alternative to them. However, his theory of legal reasoning, which is prior to his views on those issues, appears either to assume or to be compatible with familiar positivist themes, and for this reason $I$ have found it helpful more often than not to view Gottlieb's position as a development of positivism rather than as an alternative to it. In any event, the position is sophisticated and for the most part carefully worked out, and therein lies the interest of Gottlieb's work.

In what follows I consider Gottlieb's view of legal reasoning first, since it governs all else. Then I discuss his treatments of the relation of law and morality and of the nature of decision-making in an institution like the United States Supreme Court, topics which exhibit fairly well how Gottlieb intends his account of legal reasoning to be utilized. He gives attention to other problems of jurisprudence, of

$\dagger$ Associate Professor of Philosophy, Oberlin College. B.A. 1959, Indiana University;

M.A. 1961, University of Kansas; Ph.D. 1964, Yale University.

1. G. GOTTLIEB, THE LOGIC OF ChOICE (1968) [hereinafter cited as GotTLIED]. 
course, and often in instructive ways, but I will not take space to consider them here.

\section{II.}

Gottlieb devotes about half his text to the task of characterizing "legal rationality," a discussion which leans heavily upon recent philosophy of mind, meaning and language, especially as that body of theory has centered around the work of Wittgenstein in the Philosophical Investigations. ${ }^{2}$ In general, reasoning in legal contexts is said to belong to the genus "reasoning with rules," as does reasoning in moral and aesthetic contexts; and an adequate account of it will require a listing of what Gottlieb calls the "necessary ingredients" of such reasoning, together with a description of how these ingredients are deployed by those who engage in it to provide decisions for human action. Among the distinguishable ingredients of reasoning with rules, Gottlieb lists: (a) facts on record, (b) preexisting rules or precedents, (c) the processes of inferring (which include selecting "material" facts from the facts available and proceeding from material facts to a conclusion), (d) the statement or formulation of the inferences drawn, (e) the "enunciation" of the rules justifying the inferences, (f) the decision or verdict itself, (g) the consequences of the decision for the parties directly involved, (h) the foreseeable applications of the enunciated rule, with their consequences, and (i) the purposes, ends, and goals of the preexisting rules, together with the purposes that compete with them, and the different weights they may be assigned. ${ }^{3}$

As the size of this catalog suggests, reasoning with rules is a complex matter for Gottlieb. The theorist's jobs of showing how these ingredients are related and of describing the patterns of thought that constitute rule-guided reasoning are accordingly multi-faceted. Gottlieb carries out these tasks more in the manner of a survey of some recent philosophical literature than a presentation of arguments for the view's he favors. As a survey it suffers from unevenness regarding the degree of background familiarity with philosophical problems the reader is presumed to bring to the subject.

Two points seem to govern Gottlieb's treatment of reasoning with rules, and therefore to control his approach to jurisprudential problems. The first of these is an acceptance of a basic distinction between

2. L. Wittgenstein, Phinosophical Investigations (G. Anscombe transl. 1953).

3. GOTTLIEB 77, 170-71. 
"fact" and "value," 4 such that reasoning with rules is construed as a way (but not the only way) of moving from what is given to what is to be done: specifically, it is that way which proceeds by means of "inference-guiding devices" (rules) leading to decisions. ${ }^{5}$ The second point is that there is a conceptual link between rules and purposes ${ }^{0}$ such that the inference-guiding devices which carry us from facts to decisions can themselves be objects of considered preference, and thus intelligent choice, by reference to purposes. These points are not argued for in any independent way by Gottlieb, even though they are reflected in many of the jurisprudential views he later presents. ${ }^{7}$ For that reason the characterization of rule-guided reasoning that rests on them may not be of special interest to moral philosophers except for the detail in which it is set out. ${ }^{8}$ This of course does not prevent his use of the characterization in treatments of jurisprudential issues from being of interest to philosophers of law.

Aside from these philosophical commitments in Gottlieb's account, he proffers a claim about reasoning with rules which his discussion leaves confused. The claim is that reasoning with rules is "auton. omous." Gottlieb's discussion allows two interpretations of the claim, one of which seems misleading as well as unnecessary for his purposes, while the other is probably correct but of less importance than Gottlieb appears to attach to it.

According to the first interpretation, the claim of autonomy may be construed as the view that reasoning with rules is one of several "forms of reasoning," such as deductive reasoning, inductive reasoning,

4. See, e.g., id. 54 .

5. Id. 37 .

6. Id. 62, 106.

7. For a useful collection of recent materials concerning the first of these points-including some which suggest that the distinction between fact and value is not as firm as Gottlieb assumes-see THE Is-OUGHT QUESTION (W. Hudson ed. 1969). As regards the second point, perhaps Gottlieb intends as support of a sort his remark that a "gratuitous" rule, e.g., a sign in the middle of a pond saying, "Do not attach boats to this sign," is not really a rule. GoTTLIEB 62 .

8. One interesting feature of Gottlieb's characterization is that rules are to be distinguished from commands. GorTLIEB 42, 100-1, 116. How the distinction is to be made out is not completely clear from Gottlieb's discussion. His point is not that rulcs are linked with purposes but commands are not. And it cannot be merely that rules introducc recurring patterns while commands are "addressed ad hominem" (id. 42), for commands can introduce recurring patterns as well. His suggestion appears rather to be that reception is different in the two cases, in that obedience is required of the recipient of a command, whereas the recipient of a rule has an opening for appraisal and consideration of purposes. Id. 115-16. The contrast is an interesting one, but it is perhaps not sufficient as a ground of the distinction: if I command you to do $x$, and you proceed to appraise such purposes as are involved either as or before you do $x$ (or refuse to do $*$ ), it is not plain that $I$ have not commanded you to do $x$, or that you have not been commanded to do $x$.

9. Id. 28-32. 
"scientific" reasoning, etc., which stand as alternatives to each other. On this account, the concept of rationality is pictured as a collection of independent unit-activities, each with its own "logic" and internal standards in terms of which it may be distinguished from other unitactivities belonging to the general (collective) concept. Much in Gottlieb's discussion supports this interpretation. For example, he suggests that concepts of validity are "field-dependent," i.e., dependent upon "fields of argument," such as mathematics, judicial and moral decisionmaking, perhaps aesthetics; and he comments in a quasi-historical way on the "displacement of the analytic [i.e., deductive] ideal" as the paradigm of rational activity. ${ }^{10}$

But the difficulties in this picture may be troublesome enough to make it unattractive as a governing conception for the analysis of legal and other "forms" of reasoning. In the first place, to say that concepts of validity are field-dependent is to say that fields are prior to concepts of validity. This, in turn, is to say that in order to understand a specific concept of validity one must first understand the nature of a given field. But what is it to understand the nature of a field? Surely a major part of understanding "fields" is comprehending the arguments appropriate to them, and thus the concepts of validity that operate in them. That is, an understanding of these arguments and concepts would appear to be constitutive of an understanding of these fields, and not "dependent" upon them. If so, it cannot be supposed that we may approach an understanding of legal rationality by somehow first understanding law.

In the second place, the picture in question appears to warrant talk about rationality wherever there exists a recognizable "field." Thus, we are led to suppose that astrology as well as law, and cooking as well as mathematics, have their appropriate concepts of validity, and hence that we can exhibit their logics. This point is not by itself a difficulty, of course, for in a muted sense of "logic" which refers to the fact that a particular object of study exhibits patterns and structure, astrology and cooking do indeed have their respective logics. The difficulty arises when we recognize that ordinarily the task of exhibiting the concepts of validity operating in a field is taken to be the task of making clear not only the patterns of thought typical of that field but also what it is about them that makes the field, so to speak, intellectually respectable.

Now, a general way of showing that a field is not intellectually

10. Id. $28-30$. 
respectable is by showing that the patterns that characterize it do not deserve confidence. And this may occasionally be done by showing that the "inferences" sanctioned by the "logic" of that field are bogus. To make out a case of this kind presupposes that there are unacceptable as well as acceptable criteria of valid inferences and hence concepts of rationality. Against this background, the difficulty in Gottlieb's picture of field-dependent forms of reasoning is that the picture does not itself provide a distinction between acceptable and unacceptable "logics." Gottlieb recognizes this difficulty when he refers to the danger in the "displacement of the analytic ideal" of an "unchecked proliferation of new critical standards."11 What is not recognized is that the provision of means for making the distinction in question requires a proposal of criteria of acceptability for logics which is independent of the picture of alternative forms of reasoning. It may not be logically impossible to supplement that picture with criteria of acceptability for some logics over others. But, so far as justification is concerned, these criteria will occupy a kind of limbo. They certainly will not derive from the picture itself. ${ }^{12}$ In the end, the present interpretation of Gottlieb's claim that legal reasoning is autonomous does not allow us to mark off the class of rational activities within the much larger class of pattern-exhibiting fields, and hence does not itself entitle us to view the pattern-exhibiting field of law as a rational activity.

I will mention finally that this interpretation of Gottlieb's claim implies that deduction, induction, and so forth, have no place in legal reasoning, for they are to be viewed as independent forms of reasoning. But Gottlieb's own text provides objections to this. In some places he suggests that specimens of reasoning in legal contexts can be cast into deductive forms, ${ }^{13}$ though it may be unhelpful for some purposes to do so. And it seems clear that the general thrust of his account is that rule-guided reasoning is a matter of matching up "material" facts with the antecedents of rules, so that one can move by the rules to decisions which instantiate the consequents of those rules. Deductive reasoning, in short, is not the whole of legal reasoning, but nevertheless

11. Id. 30.

12. Gottlieb provides a very brief discussion and proposal of such criteria. Id. 90.82 . If my remarks are correct, the general point is that the picture of alternative forms of reasoning must leave the source of such criteria (whatever they are) unclear, and their credentials as "conditions of adequacy" suspect. At present I do not trust iny understanding of the nature and source of the criteria which Gottlieb proposes enough to discuss them specifically.

13. Id. $17,166$. 
it has a place in understanding both its structure and the operations of those who engage in its practice.

This last point suggests a different interpretation of Gottlieb's claim about autonomy, according to which the point of importance is that the schemes of deductive inference-e.g., " $p \rightarrow g, p . \therefore q^{\prime \prime-d o ~ n o t ~ p r o v i d e ~}$ a complete account of the workings of legal reasoning. Before and beyond the application of such schemes of inference are the tasks of interpreting facts and consequences in such a way as to bring them within the criteria of the variables specified in rules, of identifying and determining the merits of regarding those criteria as linked in various ways in the first place, and so forth..$^{14}$ The value of Gottlieb's view that there are "ingredients" of legal reasoning is that it suggests that many constituent tasks of different kinds are involved in decisionmaking in legal contexts. An illuminating characterization of legal reasoning cannot contain simply a recital of schemes of deductive inference, and legal reasoning may be said to be autonomous in the sense that it is not reducible to those schemes. But it does not follow that legal reasoning is autonomous in the sense that it is an independent alternative to deductive reasoning. ${ }^{15}$

III.

I turn now to Gottlieb's treatments of two connected problems in the philosophy of law: the problems of how law and morality are related, and of how "constitutional adjudication," as practiced by the United States Supreme Court, is to be understood. The interest of Gottlieb's treatment of the first of these problems is his claim, to be discussed in this section, to have escaped the approaches characteristic of positivism and natural law philosophy. Both treatments exhibit a way in which, as he admits, his general theory is incomplete, and I will comment upon the importance of this incompleteness in the last section of this review.

The point of departure for Gottlieb's account of the relation of law

14. Id. 17,166 .

15. One of Gottlieb's purposes in his discussion of the logic of legal reasoning is to provide an objection to "mechanical interpretation of rules." Id. 45-46, 126. But it is not necessary to hold that legal reasoning is autonomous in the sense of an independent alternative to deductive reasoning to provide such an objection. The vicw that legal reasoning involves but is not reducible to deductive reasoning an provide a basis for an objection to mechanical interpretation, thaugh perhaps not a sufficient basis, depending upon what conception of that form of interpretation is at issue. 
and morality is Professor H. L. A. Hart's treatment of the "rival" positivist and natural law approaches to that relation: ${ }^{10}$

Hart impliedly suggests that there is no third option and that one must adopt either of these two theories. He pointed out that uncler the positivistic view there is no logical restriction on the content of the rule of recognition which could theoretically provide that laws should cease to be regarded as such should they prove to be morally objectionable. The objection to such a theoretical arrangement would be, he felt, not logic but the gross indeterminacy of such a criterion of legal validity.

Our objection to Hart's treatment of this subject is that his dichotomy is artificial and that it leaves no room for a different mode of dealing with legislation which meets the formal tests of the rule of recognition of a system, and which is at the same time fundamentally outrageous to the moral sense of a community. ${ }^{17}$

Before attempting to understand what "different mode" of dealing with legislation Gottlieb has in mind, we should recall some themes of the positions he wishes to move away from, as well as the issue between them. On the side of positivism, the above passage suggests that among those themes will be (1) that law and morality are clistinct, in the sense that the criteria of a rule's being a legal rule are not the same as the criteria of a rule's being a moral rule, and (2) that it is not logically impossible for a morally objectionable rule to meet the criteria of a legal rule. Gottlieb does not describe the contents of a natural-law position, other than to mention that such a position "excludes from 'law' all such morally offensive rules." 18

The main issue between positivism and a natural law position, as regards the relation between law and morality, might be expressed in the following way. Suppose a rule $r$ meets the formal tests by which any rule becomes a part of a community's legal system, i.e., it has the community's "rule of recognition," in Hart's phrase, applied to it. But suppose $r$ is also morally outrageous to many members of the community, including many members of its judiciary. I take it that the typical recommendation of natural law theory in such circumstances is that the proper course for those who object to $r$ is for them to argue that $r$ is not a law, on the ground that it is morally objectionable. And the typical recommendation of positivism is for those who object

16. See H.L.A. HART, TyE CONCEPT OF LAw (1961). See also Hart, Posilivism and Ille Separation of Law and Morals, 71 HARv. L. REv. 593 (1958) and Fuller, Positivism ancl Fidelity to Law-A Reply to Professor Hart, 71 HaRv. L. REv. 630 (1958).

17. GotTLIEB 125.

18. Id. 
to $r$ to admit that $r$ is a law, but then to take steps to show how $r$ is morally objectionable, so as to bring about efforts toward its reform or abolition by citizens and resistance to it by members of the judiciary. The issue, then, concerns not whether it is legitimate to bring moral objections against rules, but whether such objections can have the effect of denying the title of "law" to rules which fall under the rule of recognition of the legal system.

Against this background, what is the "different mode of dealing with legislation" that Gottlieb has in mind? He writes:

Essentially under the alternative excluded by Hart's dichotomy we would consider as ineffective the enactment of laws which are fundamentally inimical to the purposes and goals promoted by the rules of recognition and other fundamental legal rules of the system. ${ }^{19}$

That is, the recommended course is for those who object to $r$ to argue that $r$ is not a law, on the ground that it does violence in some basic way to the purposes of the community's legal system. In accordance with his view that there is a conceptual link between rules and purposes, Gottlieb argues that

the application of the rule of recognition, like the application of all other rules, cannot be made in disregard of the ends for which it is designed. To apply ... the rule of recognition so as to allow the introduction into the legal system of rules destructive of the very ends and purposes which the rule of recognition is designed to promote, would be a self-contradictory and, therefore, absurd enterprise. 20

Let me point to certain difficulties in Gottlieb's account. First, the account does not provide an alternative to positivism and natural law theory, so far as the status of a rejected rule is concerned. If the problem is about whether $r$ is to be characterized as a morally objectionable law or as morally objectionable and therefore not a law, then Gottlieb's account is not an alternative to the positions in question, but is located on the side of natural law theory. For when a rule is rejected in the way Gottlieb proposes, it is rejected as failing to be a law.

More important, the account risks missing the issue between positivism and the theory of natural law. Since, on Gottlieb's view, there is a conceptual connection between rules and purposes, then, when $r$ is rejected on the ground that it is inimical to the purposes of a system's

19. Id.

20. Id. $125-126$. 
rule of recognition, the logic of the rejection is that $r$ does not meet the criteria of being a legal rule in that system. That is, the candidatc. rule does not pass the test of the system's rule of recognition. But positivism and natural-law theory both subsume this "mode of dealing with legislation," and do not exclude it. The issue between them is posterior to it. That issue only arises when it is agreed that $r$ has met the "formal" criteria of being a legal rule, for only then would it be problematic whether or not $r$ 's being morally objectionable is a consideration which counts-logically retroactively, as it were-is denying $r$ the title of "law." 21

Gottlieb's text indicates that he might reply to this line of criticism by arguing that the mode of dealing with legislation he has in mind is not a "moral" mode at all:

Morality is ... not directly relevant here. The rationality of purposive interpretation is logically quite neutral as to the contents of the rules and the nature of their purpose. It merely requires that interpretation is integrated with, rather than truncated from, the body of purposes it is supposed to serve. The rationality of this kind of interpretation is largely a matter of its consistency.22

Perhaps this point about moral neutrality makes Gottlieb believe he has escaped the dichotomy of positivism and natural law theory. But I do not see that he provides arguments of the right sort either to support the point itself, or to show how the point is of a kind to permit an escape from the dichotomy.

Surely a paradigm of a moral objection to a rule is one which slows how it violates or fails to serve the "moral ends and purposes" of a community, as they may be incorporated "into formal constitutional texts and declarations of a legal nature." ${ }^{23}$ The member of a community who raises these purposes against the introduction of a rule is framing a case of a familiar kind for regarding the rule as morally objectionable. There may of course be other ways of bringing a moral objection against a rule, and there may be certain purposes of a community which are not proper objects of appraisal as either moral or immoral. But both positivist and natural law theories are, by themselves, quiet on these subjects, in the sense that there are different moral theories

21. It may be objected that I have mislocated the issue, and that the natural law theorist is really proposing that moral criteria be included among the "formal" criteria of $r$ 's being a legal rule. Perhaps so. But in that case $I$ do not see how to distinguish the natural law position from Gottlieb's position, which reinforces the thought that Gottlicb either misses the issue or his position ends up on the natural law side of it.

22. GotTLIEB 128.

23. Id. 
about them, such as utilitarianism, Kantianism, etc., which each may be compatible with. The effect of this, for Gottlieb's argument, is to place upon him the burden of showing what is to count as a moral objection and what is not, and what purposes are proper objects of moral appraisal and what are not. He does not discharge this burden, and in the absence of an account which does, the reason why we must suppose that "purposive interpretation" is morally neutral remains obscure. It may be granted that such interpretation is itself independent of specific purposes and goals of systems. But this does not make the mode of dealing with legislation, whereby a system's moral ends and purposes are brought against a rule's being regarded as a law, a morally neutral mode.

This brings me to a final point concerning Gottlieb's view which is independent of how far it is an alternative to positivism and natural law theory, or whether it misses the issue between those views, or whether it can be subsumed by either of them. Gottlieb speaks in various ways about introducing rules into a system which go against its purposes: in places he describes the introduction of such rules as "logically absurd;" in other places as "ineffective;" in other places as "fundamentally inimical" to the system's ends. Without attempting to sort out these modalities, one must notice that the general effect is to place in jeopardy the possibility of a legal system's reforming itself. Legal systems promote many ends, and some of them may not have the moral credentials of others. Suppose that a system promotes Equality by, among other things, presuming that citizens are equal before the law, but that it also promotes the interests of a certain segment of the community by, among other things, restricting the notion of "citizen" to apply to members of a certain class or race. We might hope that members of the judiciary, and the people generally, would resist pieces of legislation that were in accord with the second as well as the first of these ends. They could not find aid for their efforts at resistance in Gottlieb's mode of purposive interpretation. What we might want to see happen is precisely the introduction of rules which violate the second end, and, in fact, eliminate that end from the body of purposes and goals of the system. That is, we might want to see the community move toward an enlargement of the sphere within which it follows principles associated with the ideal of Equality, by removing an artifcial restriction on the scope of application of those principles. If Gottlieb's purposive interpretation is the only mode available, then the legal system loses an important way of reforming itself. If it is not the only mode available, then, as I read Gottlieb's text, his account does 
not make clear what the others are, nor how they rank in importance with purposive interpretation.

IV.

But how problematic the prospects for the internal reform of a legal system are made by Gottlieb's view is not finally determinable by in. vestigation of the text under review. For the character of those prospects will depend ultimately upon views about the morality of ends and purposes that Gottlieb does not develop in the present text, but proposes "to explore in another work." 24 There is usually nothing objectionable in a theorist's setting limits upon his inquiry, so long as those limits do not implicitly beg the questions he sets out to answer. In the present case, however, what is set outside the inquiry is of enough importance to make the absence of discussion of it pose a threat to certain results of the inquiry. Let me show this by a brief discussion of Gottlieb's treatment of constitutional adjudication in the Supreme Court.

The problem of constitutional adjudication is set out by Gottlieb in the form of a dilemma:

The Supreme Court is . . . torn between the conflicting requirements that its appraisal of competing values and interests be principled and based upon reason, a requirement which cannot be met according to some contemporary philosophical traditions, and ... the requirement that it refrain from turning into law the shifting value preferences of the transient court majorities substituting their private preferences for those of elected legislators. Viewed in this perspective the critical question for constitutional adjudication is whether courts have the possibility to avoid this dilemma; whether they can avoid deciding issues involving conflicting values otherwise than on the basis of subjective personal preferences, on some sort of principled basis. In other words, is the dichotomy of "balancing" versus "principled" decision-making inescapable? ${ }^{25}$

Gottlieb's solution of this problem rests on the key notion of "balancing guided by preferred values"26 and requires that the "preferredness" (as Gottlieb terms it) have its source outside the subjective preferences of members of the courts directly engaged in constitutional adjudica- 
tion. In particular, the guiding preferred values should not be those of judges reacting to cases before them, but those which Gottlieb calls "preferred balances," struck by the Framers of the Constitution, "i plus those, which he calls "indications of exemplary choices between values" endorsed in "acts of national commitment," such as are to be found in documents like the Universal Declaration of the Rights of Man and the United Nations Charter, and which may be thought of as "incorporated into the law of the land under the Supremacy Clause." The advantages of this solution, Gottlieb suggests, are that preferredness of this kind "involves an element of guidance and principle which can remove the decision from the unfettered discretion of the deciding judge," and it thus "provides a fount of principle and authority which the ad hoc balancing of values assigned equal weight denies."

When judicial reasoning is committed to follow all available authority and guidance it is not faced with the awesome task of constituting its own values. This is the task of the Founders, of the Framers, not the task of judges. When there is readiness to act upon someone else's balancing, much of the anxiety and agony of decision is removed. In reasoning guided by rules there is therefore a way of being principled without legislating one's own preferences into law. ${ }^{30}$

My comment on Gottlieb's solution here is not that it is wrong. It is rather that I cannot tell whether it is right or wrong. The reason is that a solution of Gottlieb's sort raises a large number of questions, many of which are serious enough to make it useless, in the absence of a systematic discussion of them, which Gottlieb does not provide, to venture an appraisal of the solution. The questions raised are roughly of two kinds. They concern, first, the qualifications that must accompany the solution, e.g., about those cases for which preferred balances have not been established or are unclear, and about those conditions under which established preferred balances may legitimately be disregarded. ${ }^{31}$

27. "For example . . . the interest in the safeguard of internal order by government regulation has been subordinated by the Framers to the interest in the safeguard of the freedom of speech." Id. 150 .

28. Id. $148-49,152$.

29. Id. 150 .

30. Id. 151 .

31. Gottlieb remarks that in cases of the former kind, "the dilemma is then hard indeed," id. 151, which is perhaps true though unhelpful. Regarding conditions of the latter sort, he suggests that established preferred balances may be disregarded in " $\mathrm{cx}$ treme circumstances"- " "[e]xtreme" that is with respect to the overwhelming impact which failure to disregard the rule would have on a less favored value, which although less favored, is nonetheless not entirely disregarded." Id. 150. The notion of "overwhelming impact" seems as unhelpful in this context as the notion of "extreme circumstances." And 
And, second, they concern matters of justification that, if treated in appropriate detail, would require a full-blown moral theory. I will close with some remarks about questions of the latter sort that are raised by Gottlieb's solution, but left undiscussed in the present text, with the effect, I am suggesting, that his solution cannot be appraised.

I mentioned earlier that Gottlieb's view of "purposive interpretation" jeopardizes the possibility of a legal system's reforming itself. In a similar way his present doctrine of constitutional adjudication is compatible, so far as the present text is concerned, with morally objectionable "established preferred balances." In contrast, the impression I have received from Gottlieb's use of examples throughout his book is that he believes there to be some balances among competing or conflicting values which deserve preference over others. What his present account lacks, and what is promised in another work, is a theory which either sets out criteria of "preferredness," or in some other way lets us see how and why certain balances are to be preferred over others.

In the absence of such a theory, the idea that the preferences of judges engaged in adjudication should be set aside in favor of the balances struck by the Framers, plus those expressed in certain other documents the community has endorsed, ${ }^{32}$ is not itself compelling. I am not denying that the idea can be made compelling, but pointing out that arguments that might do so are not attempted in Gottlieb's text. What, after all, sanctions the move from "preferred balancings" to "Framers" preferred balancings"? The purposes of the Framers as expressed in the Constitution and commented upon in other documents can be as much compromised as those of others; The Federalist makes such a general point, ${ }^{33}$ and the three-fifths rule in the Constitution provides a specific example. Besides, the force of Gottlieb's earlier chapters was to show how the conceptual link between rules and purposes makes rules proper objects of intelligent choice and considered

Gottlieb's attempt to illustrate his point-by remarking that the preferred balance in favor of freedom of speech in the Bill of Rights "is such that it would tax the imagina. tion to conceive of any speech, as distinct from conduct, which could lead to stich an overwhelming and immediate threat to internal security as to warrant regulation," id. 150 -deserves the reply that the point depends on whose imagination is involved, and, more seriously, on how the distinction between speech and conduct is made out.

32. The fact that Gottlieb allows preferred balancings that might be found in doct. ments other than a community's constitution is interesting in its own right. On the one hand, it brings up the problem, also left undiscussed in the text, of when something is to count as a source of "authoritative balancing," $i d$. 149, for a community. On the other hand, it shows that Gottlieb does not view the preferred balancings of the Framers as exhaustive of the class of such balancings, and hence suggests that something other than those preferences stands as a criterion for them.

33. The Federalist No. 54 (Hamilton). 
preference. It is precisely this view which creates an extra need for arguments to support the claimed priority of the preferred balancings of the Framers in the present context.

Finally, Gottlieb claims that by moving from the preferences of engaged judges to those of the Framers plus others endorsed by the community, we achieve "the possibility of fairness and impartiality." ${ }^{3+}$ In the absence of a justificatory theory of preferred balancings, this claim can only be puzzling. How is it that a move from the balances of values that a judge or judges might deem preferred to those expressed in certain documents drawn up by Framers or others is a move toward even the possibility of impartiality? One might suppose that it would depend on how closely and how often the balances of either party meet the criteria of moral preferredness, whatever they are. Gottlieb's account seems to deny, without discussion, an important tradition of moral thought, according to which impartiality may indeed require the setting aside of one's own values, but not merely to replace them with the values of others, no matter how revered and estimable they may be. $^{35}$ I quoted Gottlieb above as saying that "when there is readiness to act upon someone else's balancing, much of the anxiety and the agony of decision is removed." This may be true enough in itself, but it does not yet follow that the decision-making thus relieved is morally tenable.

34. GotTLIEB 153.

35. I have in mind the Kantian tradition. The most interesting recent formulation of that tradition with which I am acquainted is the work of John Rawls. See Rawls, Justice as Fairness, 67 PHIL. Rev. 164 (1958), revised and reprinted in 2 Punosopmy, POLIIICS, AND SocietY 132 (P. Laslett \& W. Runciman eds. 1962); Rawls, Distributive Justice, in 3 Phmosophy, Potrmics AND SocirTy 58 (P. Laslett \& TV. Runciman eds. 1967). I have discussed Rawls's view in Contractualism and Mforal Criticism, 23 REv. METAPHYSICS 85 (1969). 
